\title{
Evaluation of Quadriceps Strength Post-medial Patellofemoral Ligament Reconstruction Using Quadriceps Tendon Autografts
}

\author{
Sholahuddin Rhatomy ${ }^{1,2 *}$, Roy Lisang ${ }^{3}$, Noha Roshadiansyah Soekarno ${ }^{4}$, Bambang Kisworo ${ }^{5}$ \\ ${ }^{1}$ Department of Orthopaedics and Traumatology, Dr. Soeradji Tirtonegoro General Hospital, Klaten, Indonesia; ${ }^{2}$ Faculty of \\ Medicine, Public Health, and Nursing, Universitas Gadjah Mada, Yogyakarta, Indonesia; ${ }^{3}$ Department of Orthopaedics and \\ Traumatology, Awal Bros Hospital, Pekanbaru, Indonesia; ${ }^{4}$ Department of Orthopaedics and Traumatology, Dr. Chasbullah \\ Abdulmadjid General Hospital, Bekasi, Indonesia; ${ }^{5}$ Department of Orthopaedics and Traumatology, Panti Rapih Hospital, \\ Yogyakarta, Indonesia
}

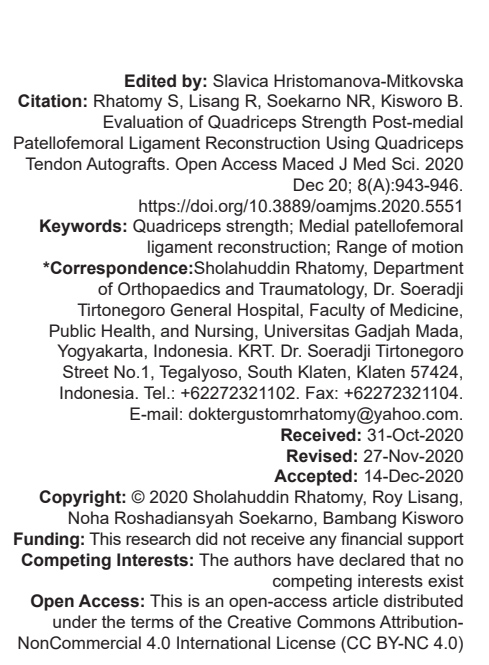

\section{Abstract}

BACKGROUND: Medial patellofemoral ligament (MPFL) reconstruction using quadriceps tendon (QT) grafts provides favorable results with minimal complications and can be performed in patients with open epiphyseal plates. Following MPFL reconstruction using QT grafts, the outcomes have been evaluated, but the residual quadriceps strength (QS) has never been evaluated.

AIM: We analyzed the knee's range of motion (ROM), thigh circumference (TC), and QS at donor leg sites compared with those at contralateral healthy sites after MPFL reconstruction. The hypothesis was that there is no morbidity at donor sites.

MATERIALS AND METHODS: Patients who underwent MPFL reconstruction using QT autografts between January and December 2017 were recruited. The ROM, TC, and QS were measured 6 months postoperatively.

RESULTS: Twenty-one patients ( 8 men, 14 women; mean age, $28.40 \pm 10.78$ years [range, 16-45]) were included in the study. The TCs at the donor and contralateral sites (medians: 37 and $37.5 \mathrm{~cm}$, respectively) showed no significan difference $(p=0.64)$. QS measurements showed means of $182 \pm 4.6 \mathrm{~N}$ and $190 \pm 4.7 \mathrm{~N}$ at the donor and contralatera sites, respectively $(p=0.376)$. There were no ROM deficits.

CONCLUSIONS: The ROM, TC, and QS at donor sites were similar to those at contralateral sites. The QT is a suitable graft for MPFL reconstruction.

\section{Introduction}

Recent anatomical and biomechanical studies have shown that the medial patellofemoral ligament (MPFL) is a primary stabilizer of the patellar bone in the position between full extension to $30^{\circ}$ flexion, as well as preventing dislocation of the patellar bone to the lateral side [1], [2].

Several MPFL reconstruction techniques have been proposed, including the use of hamstring tendons and quadriceps tendons (QTs). The use of free hamstring tendon and QT grafts in MPFL reconstruction procedures requires tunneling and anchoring of the patellar bone. Although this technique provides favorable clinical results, several complications such as patellar fracture and damage of implants have also been identified [3], [4], [5].

In 2005, Fink et al. first proposed a MPFL reconstruction method using the $Q T$, in which the $Q T$ on the patellar side is maintained (QT graft) [3]. Several studies have shown that MPFL reconstruction using a pedicled QT graft yields favorable results with minimal complications and can be performed in patients with an open epiphyseal plate [2], [6], [7].

MPFL reconstruction using a QT graft was first proposed by Fink et al., and this technique has been developed by several researchers, including Rhatomy et al. It is performed through an additional lateral release action that aims to reduce excessive pulling of the lateral retinaculum [8]. The reconstruction technique performed by Rhatomy et al. was initiated by performing lateral release arthroscopically using radiofrequency to the lateral retinaculum. Furthermore, the QT graft was obtained with the distal graft still attached to the patella, and the end of the graft was then passed through the prepared tunnel at the distal femur (Schottle point) from the medial to the lateral side [8].

The outcomes of MPFL reconstruction using QT grafts have been widely evaluated [5], [8]. However, evaluations of quadriceps muscle strength post-reconstruction using QT grafts have not been 
performed. It remains unclear whether there is a difference in the strength of the quadriceps muscle during knee extension post-MPFL reconstruction using pedicled QT grafts at donor leg sites in comparison to that at contralateral healthy sites. The aim of this study was to compare the knee's range of motion (ROM), thigh circumference (TC), and quadriceps strength (QS) between the donor and contralateral sites after MPFL reconstruction.

\section{Materials and Methods}

This was a retrospective cohort study that compared donor sites and contralateral healthy sites with consecutive sampling. Patients underwent MPFL reconstruction using QT autografts from January 2017 to December 2018. The inclusion criteria were patients diagnosed with recurrent dislocation of the patella and MPFL ruptures without bone-associated problems. The exclusion criteria were other associated ligaments/meniscal injuries, fractures around the knee, pathological tibial tuberosity-trochlear groove distance, abnormal patellar height, chondral dysplasia, and pathological problems in the lower extremities. This study was approved by the Medical Research Ethics Committee.

\section{Sampling and sample size}

The sampling design was used to select all subjects who had undergone surgery, and subjects who met the inclusion and exclusion criteria were included in the study until the study was completed.

The sample size was calculated using the following formula:

$$
\frac{\mathrm{n}=\mathrm{Z} \alpha^{2} \cdot \mathrm{P}(1-\mathrm{P})}{\mathrm{d}^{2}}
$$

$\mathrm{n}$ = sample size

$\mathrm{Z} \alpha^{2}=$ standard normal value, depending on the $\alpha$-value

$$
\begin{aligned}
& \text { If } \alpha=0.05, \text { then } Z=1.67 \\
& \text { If } \alpha=0.01 \text {, then } Z=1.96 \\
& P=\text { estimated population proportion } \\
& Q=1-P \\
& d=\text { deviation tolerance }=10 \%
\end{aligned}
$$

The proportion of patients with patellar dislocation is 5.8-77.8/100,000 population. Using the World Health Organization calculator to calculate the sample size, the minimum sample size required was five patients [9].

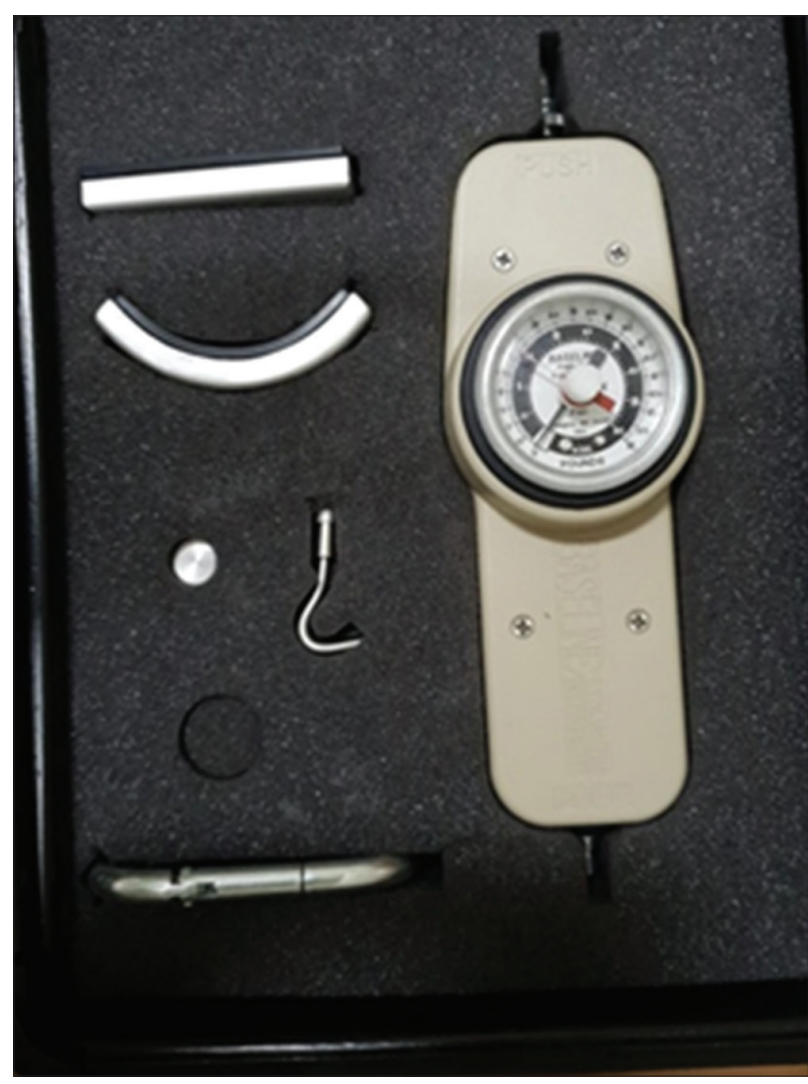

Figure 1: Dynamometer

A total of 21 patients underwent MPFL reconstruction using QT autografts. We recorded the knee's ROM and evaluated the TC and QS using a dynamometer (12-0392; Fabrication Enterprises) 6 months after the surgery (Figure 1). The measurement outcomes between the two groups were compared using the Wilcoxon test with SPSS version 25.0 (IBM). Statistical significance was set at $p<0.05$.

A single experienced knee surgeon performed all MPFL reconstructions using QT autografts. This method was based on the method described by Rhatomy et al. [8]. Graft fixation involved bioabsorbable screws (BioScrew; Conmed) on the femoral side.

\section{Rehabilitation}

A knee brace with a ROM of $0^{\circ}-90^{\circ}$ was used for 4 weeks during post-operative rehabilitation. The patients were mobilized with $20 \mathrm{~kg}$ of partial weightbearing for 3 weeks. Full weight-bearing was initiated thereafter. Passive ROM exercises to a maximum of $90^{\circ}$ were initiated immediately postoperatively. Stationary cycling was initiated 6 weeks postoperatively. A full return to pivoting sports occurred between 4 and 5 months postoperatively.

\section{Follow-up examination}

The ROM, TC, and quadriceps muscle strength tests were performed 6 months after the surgery. The 
knee's ROM was examined using a goniometer, and the TC was examined $10 \mathrm{~cm}$ from the upper patellar pole and recorded in centimeters.

The quadriceps muscle strength in both legs was measured using a dynamometer. Examinations were conducted on the bilateral thigh. The quadriceps muscle strength was measured in the sitting position. Patients were asked to perform knee extensions. The dynamometer was placed $2 \mathrm{~cm}$ below the tibial tuberosity. Each measurement was performed 3 times, and the highest outcome strength was recorded. All examinations were performed by the same operator to avoid any bias in the study (Figure 2).

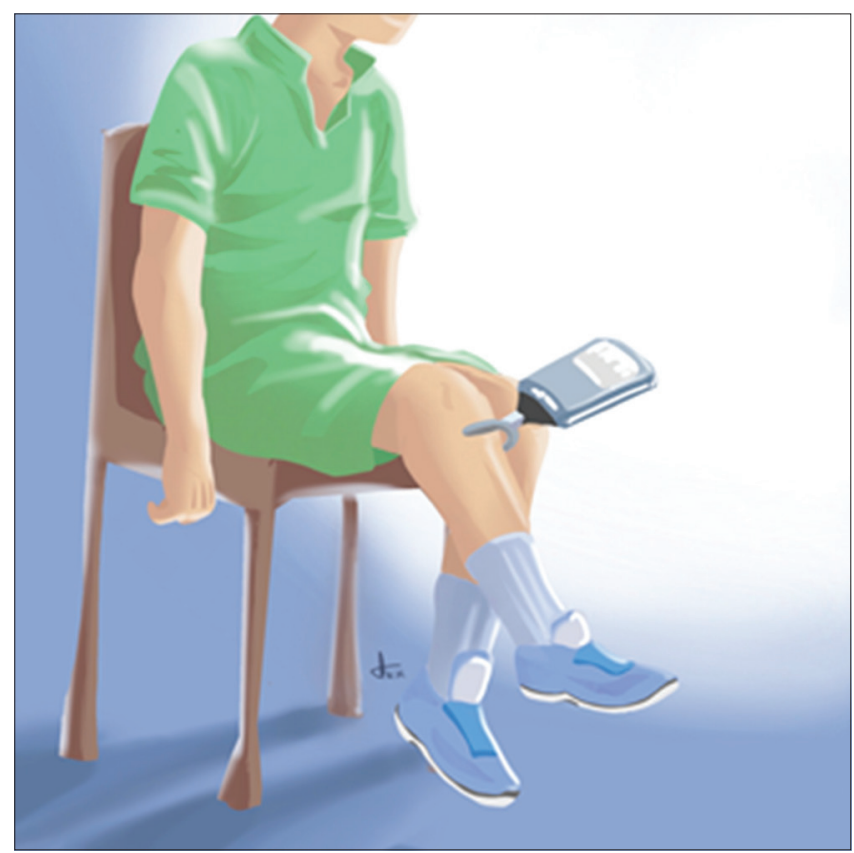

Figure 2: Quadriceps muscle strength test

\section{Results}

Of the 21 patients who were included in this study, eight were male and 14 were female. The mean age of the patients was $28.40 \pm 10.78$ years (range, 16-45 years). Sixteen patients were injured at the right knee and five patients were injured at the left knee. The mechanisms of injury were traffic accidents in eight patients, sports in six patients, and other causes in seven patients. The data on the characteristics of the subjects are presented in Table 1.

Table 1: Characteristics of the subjects

\begin{tabular}{|c|c|c|c|}
\hline Characteristics & Mean & Median $\left(25^{\text {th }}-75^{\text {th }}\right.$ percentile $)$ & $\mathrm{n}$ \\
\hline Age (years) & $28.40( \pm 10.78)$ & & \\
\hline Follow-up (months) & & $6.50(6.00-8.75)$ & \\
\hline \multicolumn{4}{|l|}{ Sex } \\
\hline Female & & & 14 \\
\hline Male & & & 8 \\
\hline \multicolumn{4}{|l|}{ Surgical site } \\
\hline Right & & & 16 \\
\hline Left & & & 5 \\
\hline
\end{tabular}

\section{TC}

The data distribution for the measurement of TC was not normally distributed; thus, the median value of the TC was calculated and the Mann-Whitney U-test was used to determine $p$-value. The median TC at the donor site was $37 \mathrm{~cm}$ and that at the contralateral healthy site was $37.5 \mathrm{~cm}$. There was no statistically significant difference in the TCs at the donor and contralateral healthy sites $(p=0.64)$. The data on TC of the subjects are presented in Table 2 .

Table 2: Post-surgical TC

\begin{tabular}{lll}
\hline Variables & Median $\left(25^{\text {th }}-75^{\text {th }}\right.$ percentile) & p-value \\
\hline Surgical site $(\mathrm{cm})$ & $37.00(35.50-40.50)$ & 0.646 \\
Non-surgical/contralateral site $(\mathrm{cm})$ & $37.50(35.75-42.00)$ & \\
\hline
\end{tabular}

\section{Quadriceps muscle strength measurement}

The quadriceps muscle strength measurement data were normally distributed; thus, the mean value was measured, and the independent t-test was used as the statistical test to calculate p-value. The mean quadriceps muscle strengths at the donor and contralateral sites were $182 \pm 4.6 \mathrm{~N}$ and $190 \pm 4.7 \mathrm{~N}$, with no significant difference ( $p=0.376)$, the data on the strength of quadriceps muscles of the subjects are presented in Table 3.

Table 3: Strength of quadriceps muscles

\begin{tabular}{lll}
\hline Groups & Mean & p-value \\
\hline Surgical site (N) & $182.0( \pm 4.66)$ & 0.376 \\
Non-surgical/contralateral site $(\mathrm{N})$ & $190.0( \pm 4.71)$ & \\
\hline
\end{tabular}

\section{Knee ROM}

There were no deficits in the ROM of the knee among all patients.

\section{Discussion}

The goal of performing MPFL reconstruction is to restore the anisometric position of the MPFL, with the aim of restoring the mobility of the patella to the femoral trochlear sulcus to normal. The MPFL is said to be anisometric because when the knee joint is in a flexed position, this ligament is stretched, and when the knee joint is in an extended position, this ligament is in a tense state (i.e., under tension) [10].

There are many MPFL reconstruction techniques, and there is no consensus as to which method is the best. The use of pedicled QT grafts for reconstruction of the MPFL has the advantage of better rotational control of the patella because the distal portion of the quadriceps graft is not removed from its insertion on the patella [3], [8]. 
Anatomical placement of the femoral tunnel may also play an important role in MPFL reconstruction. The location of the patella that is not on the anatomical side due to the placement of the femoral tunnel that is not on its anatomical side can cause a decrease in the ROM and cause pain, thus affecting post-treatment rehabilitation. In this study, an image intensifier was used to determine the anatomical location of the MPFL insertion in the femoral region [8].

Many studies have demonstrated that MPFL reconstruction is successful at restoring patellar stability with no recurrence of dislocations, improvements in knee scores, and high levels of patient satisfaction [3], [8]. However, few studies have been conducted to assess the TC and QS after surgery.

Rehabilitation after surgery is the most important factor in the success of this method in preventing quadriceps weakness. At present, no validated MPFL rehabilitation protocol exists. Some studies have outlined MPFL-specific post-operative guidelines [11], [12]. A rehabilitation program can be initiated immediately after surgery, focusing on quadriceps strengthening and ROM exercises, thus preventing quadriceps weakness.

The small number of samples was a limitation of this study, which was due to the fact that dislocation of the patella is rare. Reconstruction of the MPFL using pedicled QT grafts has the advantage of minimizing the risk of patellar fractures caused by implant use and maintaining a more stable position of the patella on the femoral trochlear sulcus; thus, rehabilitation programs can be carried out more optimally, which reduces the risk of thigh muscle atrophy and reduced thigh muscle strength.

\section{References}

1. Loeb AE, Tanaka MJ. The medial patellofemoral complex. Curr Rev Musculoskelet Med. 2018;11(2):201-8. PMid:29728862

2. Monllau JC, Erquicia JI, Ibañez M, Gelber PE, Ibañez $F$, Masferrer-Pino A, et al. Reconstruction of the medial patellofemoral ligament. Arthrosc Tech. 2017;6(5):e1471-6. https://doi.org/10.1016/j.eats.2017.06.039

\section{PMid:29354460}

3. Fink C, Steensen R, Gföller P, Lawton R. Quadriceps tendon autograft medial patellofemoral ligament reconstruction. Curr Rev Musculoskelet Med. 2018;11(2):209-20. https://doi. org/10.1007/s12178-018-9476-1

PMid:29679209

4. Azimi H, Anakwenze O. Medial patellofemoral ligament reconstruction using dual patella docking technique. Arthrosc Tech. 2017;6(6):e2093-100. https://doi.org/10.1016/j. eats.2017.08.018

PMid:29349002

5. Peter G, Hoser C, Runer A, Abermann E, Wierer G, Fink C Medial patellofemoral ligament (MPFL) reconstruction using quadriceps tendon autograft provides good clinical, functional and patient-reported outcome measurements (PROM): A 2-year prospective study. Knee Surgery, Sport Traumatol Arthrosc. 2019;27(8):2426-32. https://doi.org/10.1007/ s00167-018-5226-6

PMid:30374571

6. Nelitz M, Williams SR. Anatomic reconstruction of the medial patellofemoral ligament in children and adolescents using a pedicled quadriceps tendon graft. Arthrosc Tech. 2014;3(2):e303-8. https://doi.org/10.1016/j.eats.2014.01.005 PMid:24904782

7. Fink $C$, Veselko $M$, Herbort $M$, Hoser $C$. Minimally invasive reconstruction of the medial patellofemoral ligament using quadriceps tendon. Arthrosc Tech. 2014;3(3):e325-9. https://doi. org/10.1016/j.eats.2014.01.012

PMid: 25126496

8. Rhatomy S, Soekarno NR, Setyawan R, Primasara S, Gaol IL, Budipharama NC. Minimal invasive MPFL reconstruction using quadriceps tendon graft with lateral release: 2 years follow up. Int J Surg Open. 2019;17:20-6. https://doi.org/10.1016/j. ijso.2019.01.004

9. World Health Organization. Noncommunicable Diseases and their Risk Factors STEPS Sample Size Calculator and Sampling Spreadsheet. Geneva: World Health Organization; 2017.

10. Jibri Z, Jamieson P, Rakhra KS, Sampaio ML, Dervin G. Patellar maltracking: An update on the diagnosis and treatment strategies. Insights Imaging. 2019;10(1):1-11. https://doi. org/10.1186/s13244-019-0755-1

PMid:31201575

11. Fithian DC, Powers $\mathrm{CM}$, Khan N. Rehabilitation of the knee after medial patellofemoral ligament reconstruction. Clin Sports Med. 2010;29:283-90. https://doi.org/10.1016/j.csm.2009.12.008 PMid:20226320

12. Lightsey HM, Wright ML, Trofa DP, Popkin CA, Ahmad CS, Redler LH. Rehabilitation variability following medial patellofemoral ligament reconstruction. Phys Sportsmed. 2018;46:441-8. https://doi.org/10.1080/00913847.2018.1487 240

PMid:29888637 